\title{
Ruta turística Señorío de los Huambos para el turismo rural comunitario. Alternativa para el desarrollo del turismo y la economía inclusiva
}

Señorío de los Huambos tourist route for rural community-based tourism: An alternative for the development of an inclusive economy

\author{
Elvis Doberto Osorio Arrascue \\ Wilfredo Montenegro Carrasco* \\ Facultad de Ciencias de la Comunicación, Turismo y Psicología, \\ Universidad de San Martín de Porres, Perú
}

\section{Resumen}

Se presentan los resultados de la investigación Propuesta de ruta turística, Señorío de los Huambos para el turismo rural comunitario, desarrollada en las provincias de Chota, Cutervo y Santa Cruz, región Cajamarca, en el año 2019. El diseño de investigación es correlacional-transversal, de enfoque mixto. La muestra la integran 120 pobladores de la ruta turística, a quienes se les aplicó un cuestionario y una ficha de observación. Los resultados nos indican una correlación altamente significativa entre la ruta turística Señorío de los Huambos y el turismo rural comunitario (TRC). Nueve correlaciones específicas son altamente significativas: siete moderadas con tendencia a alta, y dos bajas con tendencia a moderada. En los resultados se muestra el orden de prioridad en la ejecución de la propuesta: las de significancia baja y moderada dependen de los resultados con alta significancia, esto evidencia que la ruta turística Señorío de los Huambos (recursos históricos, naturales y culturales) tiene las condiciones para el desarrollo del TRC, por ende, contribuye con el desarrollo del turismo y la inclusión socioeconómica de los pueblos cajamarquinos y del Perú.

Palabras clave: ruta turística Señorío de los Huambos; turismo rural comunitario; gastronomía; arqueología; atractivos turísticos

Este es un artículo Open Access bajo la licencia Creative Commons Atribución-NoComercial-Compartirlgual 4.0

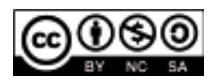




\section{Abstract}

This paper presents the results of the research Señorío de los Huambos: tourist route proposal for rural community-based tourism conducted in the provinces of Chota, Cutervo and Santa Cruz, located in the Cajamarca region, in the year 2019. The research had a correlational, cross-sectional and mixedapproach design. The sample was made up of 120 inhabitants of the tourist route, to whom a questionnaire and an observation sheet were administered. The results indicated a highly significant correlation between the Señorío de los Huambos tourist route and rural community-based tourism (TRC). Nine specific correlations were highly significant: seven were moderately to highly significant and two were slightly to moderately significant. The results showed the order of priority in the execution of the proposal: slightly and moderately significant correlations depend on highly significant results. This demonstrates that the Señorío de los Huambos tourist route (historical, natural and cultural resources) has the conditions for TRC, and thus contributes to the development of tourism and the socio-economic inclusion of provinces of Cajamarca and Peru.

Keywords: Señorío de los Huambos tourist route; rural community-based tourism; gastronomy; archeology; tourist attractions

\section{Introducción}

La ruta turística Señorío de los Huambos, ubicada en la región Cajamarca, abarca cuatro corredores: Huambos, Chota, Cutervo y Santa Cruz, todos ellos ricos en recursos históricos, naturales y culturales. Lo que convierte a esta ruta en un gran potencial para el desarrollo del turismo rural comunitario (TRC), y por ende, del desarrollo y la inclusión socioeconómica de sectores pobres de Cajamarca y la sociedad peruana. Paradogicamente, a pesar de la riqueza del lugar, existe una profunda crisis, marcada por la indiferencia de sus autoridades y la ausencia de políticas de descentralización y desarrollo. El abandono, la depredación de los monumentos arqueológicos, la falta de investigación científica y mantenimiento de áreas naturales y arqueológicas, así como la informalidad, evidencian esta crisis; situación que los ha postergado y que condena a estos pueblos al subdesarrollo y la pobreza (Osorio, 2019). 
El turismo de la zona se caracteriza por su informalidad. El transporte, a pesar de contar con una pista asfaltada, solo cubre el traslado de personas y carga, no cuenta con un servicio exclusivo y preparado para el turismo. Para llegar a las zonas turísticas, la caminata, la cabalgata y el ingenio prevalecen. La información proviene de la buena intención de los pobladores del lugar, se carece de una información sistemática y cultural. El hospedaje, a pesar que se han implementado hoteles y hostales, es precario y limitado para atender de manera integral al turista. La oferta gastronómica, basada en su amplia variedad de productos, es informal, improvisada y precaria (Osorio, 2019).

Por eso, nos sentimos motivados a difundir los hallazgos de la investigación titulada Propuesta de ruta turística Señorío de los Huambos para el turismo rural comunitario en la provincia de Chota, Cutervo y Santa Cruz, región Cajamarca. En ella se plantea como objetivo determinar la relación entre la ruta turística Señorío de los Huambos y el TRC. Se centra en el avance de la investigación científica aplicada al desarrollo del turismo y la gastronomía, lo que a su vez, permite la difusión de los diversos recursos históricos, naturales y culturales, así como el proceso de inclusión socioecónómica de las zonas rurales, el desarrollo económico y desarrollo cultural de la región Cajamaca y el Perú (PROMPERÚ, 2003). La hipótesis planteada es que existe una relación significativa entre la ruta turística Señorío de los Huambos y el TRC.

\section{Ruta turística Señorío de los Huambos}

Este es un proyecto en etapa de implementación, Huambos, toma su nombre de la etnia preinca, los Wambos, dominio Yunga, que se desarrolló durante el gobierno del Gran Régulo, residente en el valle de Cajamarca, antes de la incursión del Imperio incaico (Carrera, 1644; Marreros, 2007; Osorio, 2019). Tiene 4 corredores turísticos y 10 dimensiones.

\section{Corredores de la ruta turística Señorío de los Huambos}

- Corredor turístico Huambos. De gran trascendencia por sus abundantes atractivos históricos, naturales y culturales (Tabla 1). Actualmente Huambos es distrito de la provincia de Chota, región Cajamarca que posee un territorio de $240.40 \mathrm{~km}^{2}$, a $2276 \mathrm{~m} \mathrm{~s}$. n. m. Marreros (2007) lo describe como una «meseta de bellos paisajes e impresionantes celajes, con un clima frío 


\section{Tabla 1}

Atractivos turísticos históricos, naturales y culturales de Huambos

$\mathrm{N}^{\circ}$ Atractivo Detalle

1 Iglesia matriz San Juan Bautista

2 Mirador de Aparíc

3 Túnel Aparíc - Shingocampana

4 Guanbo o Tanbo Real Inca

5 Qhapaq Ñan

6 Sitio Arqueológico de Incahuasi

7 Bosque de los cuyes

8 Laguna de Churucaga

9 Vestigios fósiles de Chentén

10 Complejo Arqueológico de Pacopampa

11 Bosque de protección de Pagaibamba

12 Catarata La Toma

13 Catarata de Chorro Blanco

14 Gruta de El Talegón del Chaco

15 Cuevas de Cusilguán
Contruída en 1560 íntegramente en piedra tallada.

Colina desde donde se puede apreciar la ciudad y los valles de Huambos.

Misterioso camino natural subterraneo.

Vestigio arqueológico ubicado dentro del mercado de Huambos.

Segmentos del camino inca (Chenten, La capilla, etc.)

Ciudadela; quedan tres murallas de piedras labradas de $200 \mathrm{~m}$ de largo cada una, en su interior tiene habitaciones en forma circular y rectangular, extendida en un área de 1002 a 3111 m s. n. m.

Atractivo natural de belleza impresionante, según los lugareños en el lugar existen cuyes silvestres.

Laguna de $300 \mathrm{~m}^{2}$ con aguas cristalinas en sus formaciones naturales que obligan al visitante a entrar en ellas sin importar el clima.

Conjunto de huellas de dinosaurios y conchas marinas gigantes petrificadas.

Centro ceremonial de piedra tallada y pulida, ubicado en el distrito de Querocoto, con una extención de $3 \mathrm{~km}^{2}$. Son construcciones de piedra con argamasa de barro. Perteneció a la cultura Pacopampa.

Atractivo natural protegido (1987) por su variada flora y fauna, extendido en 2400 ha, a 3732 m s. n. m.

Caída de agua de más de $30 \mathrm{~m}$ de altura entre las inmediaciones de formaciones rocosas extrañas (posibles fósiles de dinosaurios, tortugas y conchas marinas gigantes) (Yamaluc).

Catarata de $35 \mathrm{~m}$ de altura, rodeada de una gran laguna, exuberante vegetación y paisaje natural, en forma de abanico de color blanco.

Conjunto de formaciones rocosas, conformadas por estalacmitas y estalactitas, arrecifes de coral y estratos de carbón y petróleo.

Cueva de gran profundidad, aún incalculable.

Fuente: Marreros (2003); Martínez (2010); Osorio (2019); Ramos (2005); Rivera (2011). 
y a veces templado» (p. 4). Está situado a $55 \mathrm{~km}$ de la ciudad de Chota y $219 \mathrm{~km}$ de la ciudad de Chiclayo (Osorio, 2019).

- Corredor turístico Chota. Rico en recursos históricos, naturales y culturales. La ciudad de «Todos los Santos de Chota» fue fundada por Fr. Juan Ramírez de Taboada en el año 1552, y en 1855, fue reconocida como provincia de Cajamarca. Se ubica a $219 \mathrm{~km}$ de la ciudad de Chiclayo, a una altura de 2388 m s. n. m. Tiene una extensión de $3773.09 \mathrm{~km}^{2}$; y su temperatura promedio es de $17.8^{\circ} \mathrm{C}$. La ciudad está ubicada en la meseta de Akunta, rodeada por la cordillera de los Andes (Osorio, 2019; Roncal \& Chávez, 2016).

Según Roncal y Chávez (2016), en el año 1882, Tomasa Álvarez e Isidora Rodrigo, organizaron la estrategia de defensa del pueblo chotano frente al abuso de los invasores chilenos.

Los chilenos ingresaron a la ciudad, justo a la hora del almuerzo, al no encontrar a la gente, tomaron la comida que supuestamente, por el miedo, había sido abandonada, en las casas. iSorpresa!, la comida estaba envenenada y pronto empezaron a morir algunos soldados, hecho que enfureció a los chilenos y en venganza incendiaron la ciudad.

Felipe Guerrero y Cirilo Vera escondieron la imagen de la Virgen, la Patrona de Chota, para liberarla del incendio, la misma que fue encontrada y devuelta a la catedral 70 años más tarde. Un año después (1883) Manuel José Becerra Silva organizó el «Batallón Chota» para la batalla de Cárcamo (Miracosta), donde se derrotó a los chilenos, vengando de ese modo la afrenta del incendio de la ciudad de Chota. Fue tal la estrategia de Becerra, que, cercando a los chilenos y sus caballos en una encañada de Miracosta, los aniquiló solamente a pedradas. Los restos del enemigo nunca fueron recogidos, quedaron esparcidos hasta hoy en aquel lugar como evidencia de la bravura de los chotanos (Osorio, 2019).

Vilchez (1960), por su parte, se refiere a la revolución del bandolerismo. En enero de 1920, con la aprobación de una nueva Constitución, se inició el gobierno dictadorial de Augusto B. Leguía en el Perú. Este hecho es el inicio de una nueva revolución chotana ya que se organizó un «Comité Secreto 
Pro Revolución» contra los abusos del dictador, a él se unieron Eleodoro Benel Zuloeta y los hermanos Avelino y Andrés Vásquez Muñoz, así como un número considerado de jóvenes chotanos y cutervinos. En noviembre de 1924 estalla la revolución chotana, rescatando la ciudad de manos del dictador. En 1925 ocurre una masacre en Cutervo, donde muchos inocentes fueron asesinados por el dictador. Este hecho provocó la indignación del pueblo, que sin pensarlo mucho, determinó engrosar las tropas rebeldes de los hermanos Vásquez y Benel, por lo que fueron arduamente buscados por el ejército y la guardia civil. Los hermanos, fueron traicionados y fusilados en Cutervo (1927), mientras que Benel fue disminuido y acorralado, luego de tres años de tenaz resistencia, se inmoló con su propia arma en la espesura de la Cordillera de Tarros.

Otro tema trascendente es el de las rondas campesinas de Chota, fundadas el 29 de diciembre de 1976 en la comunidad de Cuyumalca, con el propósito de controlar el abigeato que agobiaba a los campesinos chotanos. Luego se convierte en una organización pionera y promotora de la paz y la seguridad de los pueblos cajamarquinos. Actualmente, las rondas están presentes en varias regiones del país (en zonas campesinas y urbanas), contribuyendo al orden y tranquilidad de sus poblaciones. El parque $E l$ Rondero, fue construido en honor a las rondas campesinas (SUNARP, 2017).

La lista de atractivos (Tabla 2) contiene los lugares de interés, a ellos se suman los queñuales de Choctapata, las lagunas del Amor, las lagunas de Llashavilca, los Pajonales y lagunas de Bellandina, las aguas termales de Naranjo y Ashdi, los vestigios arqueológicos de Segues (Cochabamba) y las lagunas naturales de Mishacocha y Mishahuanga (Miracosta) y otros (Sánchez, 2015).

Información igualmente importante es la referida a las expediciones científicas en Chota: Alexander von Humboldt y Aimé Bonpland (17991804); Antonio Raimondi (1859); y Augusto Weberbauer (Marreros, 2004; Roncal y Chávez, 2016). 


\section{Tabla 2}

Atractivos turísticos (naturales y culturales) de Chota

$\mathrm{N}^{\circ}$ Atractivo Detalle

1 Nacimiento del río chotano

Lugar de convergencia de la quebrada Colpamayo, Lopezmayo, río Doñana, río Vizcamayo, tunel conchano y río Chancay, en las las faldas del cerro Clarinorco y Shingueray.

2 Ojo del río conchano

Atractivo natural. Agua que nace del subsuelo, luego canalizada, para dar vida a los valles de Conchán, Chiguirip y Tacabamba y abastecer de agua al túnel conchano que beneficia a Chota y Chiclayo.

3 Valle de Tuctuhuasi

Paisajes naturales extensos con abundate flora, ubicados a orillas del río Chotano. Según la tradición, allí debió fundarse la ciudad de Chota, pero no fue posible por voluntad de Nuestra Señora de Chota.

4 Valle Doñana

Extensos campos, con variada flora, hermosas lagunas y parajes apropiados para las excursiones, el deporte y las caminatas, ubicados en la parte norte de la ciudad de Chota, a orillas del río del mismo nombre.

Presenta, una gran variedad de especies madereras (romerillo, cedro, roble,

5 Bosque el saucecillo lanche, guayacán, etc.) y plantas medicinales. Ubicado en la comunidad de Chuyabamba.

Monumento arqueologico ubicado en el cerro Cóndor Caga (distrito de

6 Chullpas de Churucancha Lajas). Compuesto por torres funerarias de cuatro pisos, con divisiones en sus interiores, es de la cultura Inca.

7 Catarata el Cóndac

Caída de agua de $60 \mathrm{~m}$ de altura (distrito de Tacabamba). Se encuentra rodeada de una diversidad de flores exóticas, frutales y cafetales.

Atractivo natural, ubicado en la comunidad de Pichugán, se caracteriza por

8 Gruta de Pichugán su profundiadad aún no determinada. Actualmente está prohibido su ingreso por los riesgos que implican la osuridad y la profundidad.

Sitio arqueológico y natural, ubicado en la comunidad de Caramarca,

9 Andenes del El Idolo presenta una forma de pirámide, y en todos sus lados se pueden apreciar muchos andenes hechos de piedra. Es característico por las piezas encontardas de piedra, arcilla y oro, se le atribuye poderes de encanto.

Monumento arqueológico ubicado en el distrito de Chiguirip. Son ruinas 10 Torres de Chiguirip prehispánicas con rasgos de la cultura Chavín, hechos de piedra, con figuras grabadas en alto relieve.

Restos arqueológicos ubicados en el distrito de Conchán. Es una fortaleza

11 Chullpas de Chetilla 0 ciudadela fortificada de la cultura Chetilla (300 a 600 a. C.). Quedan 17 chullpas separadas, y unidas a la vez, por caprichosas divisiones denominadas «torres maléficas». En su interior se observan cámaras mortuorias y grabados líticos. 
12 Chullpas y grutas de Negropampa

13 Santuario de Chucumaca

14 Gemelos de la Paccha

15 Plaza de toros «El Vizcaíno»

16 El Túnel conchano

17 Textileria ancestral de la «callua» o telar de cintura

18 Feria de san San Juan 0 San Juan Pampa

19 Fiesta de la Patrona de Chota

20 Zonas de vida en Chota
Sitio arqueológico, vestigios líticos tipo Chavín llamadas Kullpi. En las grutas, se encuentra un conjunto de tumbas subterráneas con dibujos de jaguar.

Bosque encantado extendido en 20 ha. Son unas insólitas y caprichosas figuras pétreas, cinceladas por el viento y la lluvia desde hace 60 millones de años (posiblemente de la era terciaria o cenozoica).

Monumemto arqueológico, presenta construcciones líticas preinca. Están dentro del hermoso valle Llaucano y los yacimientos carboníferos del lugar.

Construída en el año 1965 en homenaje al torero español Juan Fernández Lorenzo, quien radicó en Chota e institucionalizó las corridas de toros, años despúes fallecío en esta ciudad que guarda sus restos cariñosamente.

Construido el año 1983, es una gran obra de derivación del río Conchano al río Chotano, que mediente el tunen abastece las costas de la región Lambayeque.

Actividad cultural para crear originales obras de arte de alta calidad, belleza y colorido. En el Centro Poblado de Cuyumalca todas las familias participan de estas actividades. Los cungalpos, putecs, illaguas, trameros, prendes y calluas son las herramientas hechas de maguey, nogal y otras maderas. La corteza del aliso, del alcanfor y los frutos de nogal dan vida a los finos colores de los tejidos, hechos de lana de oveja con diseños que evocan grandes historias de amor, decepción, patriotismo o riqueza natural del pueblo chotano.

Atractivo cultural, que se celebra en junio. Miles de pobladores chotanos, acuden a Corepuquio (fuente de oro), para celebrar, al Santo del Río 0 «Santo Fiestero». Esta festividad mezcla tradiciones antiguas y modernas. El concurso la «Flor de Chot» (la belleza de la mujer campesina chotana) y la feria de platos típicos.

Atractivo cultural de orden religioso. El 8 de diciembre, de todos los años, el pueblo creyente chotano celebra la fiesta patronal en honor a la Virgen María, Patrona de Chota.

En 1947 Leslie Holdridge establece estas zonas (pisos altitudinales) con el fin de crear un sistema ecológico de alcance mundial que permite comprender las características climáticas principales de un determinado lugar. El Perú cuenta con 84 zonas de vida, 27 se encuentran en la región Cajamarca. Chota tiene tres: el bosque muy húmedo montano tropical (2800 a $3800 \mathrm{~m} \mathrm{s.} \mathrm{n.} \mathrm{m.),} \mathrm{el} \mathrm{bosque} \mathrm{húmedo} \mathrm{montano} \mathrm{bajo} \mathrm{tropical} \mathrm{(1800} \mathrm{-} 2800$ m s. n. m.), y el páramo pluvial subalpino tropical (más de 3800 m s. n. m.), presentan un clima variado y se ubican entre el distrito de Chota, Conchán y Chiguirip.

Fuente: Osorio (2019); Roncal y Chávez (2016); Sánchez (2015). 
Milton Antezana, presidente de la Asociación Cultural Ecoturística de Recuperación «Montaña», identifica a Chota como la «Hija del Machete y la Lluvia». El machete es un admirable padre, símbolo del valor y trabajo de los hombres y mujeres chotanos y la lluvia es la madre protectora, responsable del verdor y belleza de sus pletóricos valles y campos interminables (Osorio, 2019).

- Corredor turístico Cutervo. Presenta una gran riqueza histórica, natural y cultural, escenario apropiado para el turismo rural comunitario, turismo ecológico y turismo de investigación. Cutervo se ubica en la vertiente occidental de la cordillera de los Andes, en el norte del Perú. Tiene una extensión de $3028.46 \mathrm{~km}^{2}$, su clima es templado, moderadamente lluvioso y oceánico debido a que presenta una altitud muy variada, entre 400 a 2649 m s. n. m. (Cabrera, 2014).

Su historia comienza con la llegada del imperio civilizador Wari al norte de Cajamarca, aproximadamente en el año 650 a. C.; el nombre deriva del aymara kuti (acción de regresar) y del quechua kutiy (regresar, retornar). El inca Pachacútec, conquistador de Cutervo, le llamó Kutirpu (vocablo aymara que significa parcela de tierra constantemente sembrada) por su gran producción agrícola y su variedad climática (Vilchez, 1945).

En el año 1460, en pleno apogeo del Imperio inca, Cutervo perteneció al Señorío de los Wambos. Su fundación data del 15 de agosto del año 1560, a cargo del español Fr. Juan Ramírez de Taboada, quien lo hace parte del virreinato del Perú bajo el patronato de la Santísima Virgen de la Asunción. En 1825 se estableció como distrito dependiente de la provincia de Chota y en 1871 asciende a categoría de ciudad. En 1874 se inician las gestiones para convertir a Cutervo en provincia, después de muchas luchas (19031908), el 22 de octubre de 1910 asciende al rango de provincia del departamento de Cajamarca (Cabrera, 2014).

Los atractivos y sus detalles se describen en la Tabla 3, a los que se incluyen las Torres de Rejopampa, las grutas de Santa Clara, los petroglifos de Quilucat (Cujillo), las pinturas rupestres de Carborán, el bosque de Piedras, las Torrecillas de Mochadín, las iglesias de Ambulco y las cuevas de Huichud (Cabrera, 2014). 


\section{Tabla 3}

Atractivos turísticos (naturales y cuturales) de Cutervo

\begin{tabular}{|c|c|}
\hline $\mathrm{N}^{\circ}$ Atractivo & Detalle \\
\hline 1 Parque Nacional de Cutervo & $\begin{array}{l}\text { Primer Parque Nacional del Perú, ubicado en el distrito de San Andrés, a } \\
2.450 \text { m s. n. m, en una extensión de } 2500 \text { ha. Fue creado en } 1961 \\
\text { mediante Ley No } 13694 \text { impulsada por el el Dr. Salomón Vilchez Murga con } \\
\text { el objetivo de proteger las grutas de los Guacharos, su flora (orquidias, } \\
\text { palmeras o chontas y arboles madereros) y fauna jaguar, el tigrillo, la nutria, } \\
\text { el armadillo, el gato silvestre, el tapir de altura, el oso de anteojos y el gallito } \\
\text { de las rocas y Bagre de las Cavernas). Por su gran variedad de vegetación } \\
\text { es considerado el paraíso de los botánicos más grande del Perú. Es área } \\
\text { protegica por la Ley N } N^{\circ} 28860-2006 \text {. }\end{array}$ \\
\hline
\end{tabular}

Son cavernas naturales profundas (hábitat de miles de Guácharos 0

2 Grutas de los Guacharos Guaicharos, steatornis caripensis, ave nocturna, que vive en muy pocos lugares del mundo, apreciada por su estiércol, que con el tiempo se convierte en abono). Este atractivo es visitado por turistas nacionales e internacionales, interesados en la investigación.

Atractivo natural, ubicada entre 2958 y 4950 m s. n. m., en una extensión de 2950 ha. Alberga una variedad de flora y fauna silvestre, un conjunto de

3 La Cordillera de Tarros cuevas misteriosas y portentosas caídas de agua de más de $100 \mathrm{~m}$ de altura. Es lugar privilegiado e inexplorado, apropiado para el turismo ecológico de aventura e investigación. La presencia de animales salvajes y la ausencia de la autoridad, hacen de este lugar un destino poco accesible y peligroso, pero siempre un atractivo natural, único en el mundo.

Conjunto de pictografías o figuras antropomorfas, zoomorfas y fitomorfas, de

\section{Complejo Arqueológico de Llipa}

5 Complejo Ecológico el Pilco

6 Las iglesias

7 Ruinas del Paratón

8 Tragaderos de Yacuchingana color rojo. Dentro del complejo están las chullpas de Llipa: torre Colorada y torre Blanca. En su interior presentan pinturas rupestres que manifiestan figuras zoomorfas, religiosas y geométricas, posiblemente de influencia Chavín.

Es una planicie ubicada a $3000 \mathrm{~m} \mathrm{s.} \mathrm{n.} \mathrm{m.} \mathrm{(distrito} \mathrm{de} \mathrm{Sócota).} \mathrm{Presenta}$ diversos atrativos como la catarata del Pilco (caída de agua, de $80 \mathrm{~m}$ de altura), laguna del Pilco (de $730 \mathrm{~m}^{2}$ de extensión), bosque de Piedras (bloques de rocas erosionadas).

Sitio arqueológico ubicado en el distrito de la La Ramada. Presenta construcciones de piedra, en formas de iglesias.

Es una ciudadela con rasgos chavinoides, ubicada entre los distritos de Callayuc y Querocotillo.

Desague natural de la ciudad de Cutervo, ubicado en la parte más baja de la planicie endida (parecida a un perol), que obstaculiza desvio del desague de la ciudad. Es por ello que las aguas servidas de Cutervo se canalizan y desembocan en dicho tragadero. 
$\mathrm{N}^{\circ}$ Atractivo

9 Tragaderos La Colca

10 El Señor del Llucán

11 Festividades religiosas

12 Gastronomía cutervina

\section{Detalle}

Atractivos naturales ubicados en centro poblado de La Colca y las Palmas, característicos por su profundidad indeterminada.

Descubrimiento arqueológico (piezas de oro, plata y cobre): ciudadela de piedra, en la parte superior-media, del cerro llucán, a $3050 \mathrm{~m} \mathrm{s.} \mathrm{n.}$ m. dentro del complejo «los arenales» de Cutervo.

San Juan Bautista (24 de junio), Virgen de la Asunción (15 de agosto) y Virgen de la Candelaria de Sócota (2 de febrero) (Cabrera, 2014).

Cuy frito con papas, sancochado, chochoca, shurumbo, pepián, caldo de mote, caldo verde, caldo de fiambre, etc.; postres (buñuelos, Chipche $y$ alfajores), y bebidas y tragos (aguardiente, guarapo y chicha de jora).

Fuente: Fernández (2015); Ilucán (2016); Mincetur (2017); Osorio (2019); Vilchez (1968).

- Corredor turístico Santa Cruz. Presenta atractivos naturales, históricos y culturales de gran valor. Se encuentra ubicado en la provincia de Santa Cruz de Succhabamba. Estas tierras en sus inicios fueron habitadas por tribus locales y luego conquistadas por Pachacútec y Túpac Inca Yupanqui. Cuando llegaron los españoles tenía el nombre de Chapuy, ellos lo cambian a Santa Lucía. En 1950 se convierte en provincia de Cajamarca (Vargas \& Fernández, 2010).

En la Tabla 4 se detallan los atractivos de este corredor. También se suman a ellos la catarata Chorro Blanco de Pulán, la catarata el Apto, el Velo de novia de Vista Alegre, las ventanillas de El Roble, los geoglifos El Cóndor de Catache, las pinturas rupestres la Guitarra y el Calvario y el cementerio prehispánico Palo Blanco (Calderón, 2010). 


\section{Tabla 4}

Atractivos turísticos (naturales y culturales) de Santa Cruz

$\mathrm{N}^{\circ}$ Atractivo Detalle

1 Museo Arqueológico-Colonial, Colecciones de ceramicos y piezas arqueológicas de las culturas Particular Royma cajamarquinas.

2 Aguas termomedicinales de

Extendido en 2628 ha, 2035 m s. n. m., y zona reservada desde 1996. Chancay Baños. Muy visitada por sus aguas termomedicinales.

3 Parque Paleontológico Piedra Chamana

Zona de fósiles en la localidad de Sexi, a $2500 \mathrm{~m} \mathrm{~s}$. n. m. Patrimonio Cultural de la Nación por el Instituto Nacional de Cultura.

4 Manantial el Puquial

Es un manantial de agua natural. Se considera que sus aguas son milagrosas, porque a pesar de las sequías, en algunas épocas del año no deja de abastecer de agua al distrito de Sexi.

5 Iglesia de Shuyundo

Monumento utilizado antiguamente como refugio de peregrinos.

6 La Torre

Monumento arqueológico enigmático hecho en forma de mole de piedra.

7 Fuente de piedra La Dacha

Es una fuente de piedra labrada (tina gigante de piedra). Posiblemente fue utilizada por los pobladores antiguos para el recojo de agua de la lluvia.

Consideradas las cuevas más grandes del mundo, ubicadas en

8 Grutas de Ushcupishgo 0 grutas de Polulo

Ninamababa, en su interior corren siete ríos, formando tres cataratas y once lagos. Humboldt (1802) y Antonio Raimondi (1868) las visitaron con fines de investigación científica.

Reserva de vida silvestre (anfibios y lepidópteros) y agua limpia, en una

9 Bosques nublados de Udima extensión de 12183.20 ha, a 2000 y 3000 m s. n. m. El clima varía dependiendo del niven en el que se encuentra, entre los $22^{\circ} \mathrm{C}(500 \mathrm{~m})$, $18^{\circ} \mathrm{C}(1500 \mathrm{~m}), 12^{\circ} \mathrm{C}(2500 \mathrm{~m})$ y $8^{\circ} \mathrm{C}(3500 \mathrm{~m})$. Se ubica en la intercección de los distritos Catache, San Miguel y la Florida, además de la provincia de Oyotun (Lambayque).

10 Sitio Arqueológico de Templo preinca construido en piedra tallada y pulida, de diversas formas El Poro Poro y tamaño, de acuerdo a su funcionalidad. Ubibicado en el distrito de Catache.

Fuente: Calderón (2010); Osorio (2019); Vargas y Fernández (2010). 


\section{Dimensiones de la ruta turística Señorío de los Huambos}

\section{Historia, cultura y ecología}

Huambos deriva del término quechua wambos o wampu, que significa terreno agrietado y camino subterráneo (desde el Aparíc al Shingocampana). El vocablo, proviene de wamburo, un árbol nato del lugar, cuyo tronco es liviano y utilizado como camilla (Marreros, 2007).

La historia de los Huambos se remonta a la época preinca. La migración de la cultura Cicán hacia los pueblos de la sierra (1440), ubican a los Wambos en el Período Intermedio (900-1470 d. C.), época caracterizada por la fragmentación de los pueblos andinos en señoríos. Wambos, de dominio mochica, fue uno de ellos y el más destacado dentro de los cuarenta grupos étnicos del antiguo Perú; tenía una organización sociopolítica basada en pachacas y huarangas, cuyas autoridades eran los curacas o caciques. Tenía una administración política, económica y cultural propia; su lengua era el culli (Maeda, 2005; Martínez de Compañon \& Bujanda, 2012).

Marreros (2007) agrega:

Acunta, fue descendiente de Naylamp y su dios fue Chot. Los primeros que quisieron sojuzgarle fueron los Bracamoros, que no lograron sus deseos, recluyéndose éstos en la región de Jaén. Luego fueron invadidos por los Aymaras, quienes, luego, fueron arrojados por los aguerridos Wambos. (p. 29)

Las ruinas de Pacopampa (Querocoto), verdadera capital de la cultura Chavín, demuestra la presencia preinca de esta civilización (El Ushún, 2017): «Antes que el Imperio Inca alcance su esplendor, en Huambos ya existía una próspera civilización: los Wambos» (p. 6), cuyos dominios se extendieron hasta Ecuador, donde subsisten todavía las tribus indígenas de Huambas y Huambisas (Eslava, 1985; Osorio, 2019).

En la época incaica el señorío de los Wambos, que comprendía siete huarangas: Chota, Huambos, Santa Cruz, Cutervo, Sócota, Cachén y Querocoto, fue conquistado por el inca Atahualpa, durante su recorrido de Quito a Cajamarca (1455 o 1456). El inca Túpac Yupanqui sometió a este señorío, obligó a sus habitantes a rendirle culto al sol, entregar tributo al 
soberano y adaptarse a la lengua quechua. Luego, quedó bajo el gobierno de los curacas Taitacocha, Tamayoc, Chuquicóndor y Cheigo (Betanzos, 1551-1880).

En la época colonial, un 24 de junio de 1552, Huambos fue fundada como provincia por el misionero español Juan Ramírez de Taboada, con el nombre de San Juan Bautista de Huambos, como parte de las acciones de evangelización (Betanzos, 1551-1880; Osorio, 2019). Espinoza (1967), en su investigación sobre el periodo formativo, en la sierra norte del Perú, haciendo alusión a Fray Juan Ramírez (1563) y Antonio De la Calancha (1639), sostiene que en los primeros años de la conquista española, Pacopampa (Querocoto) pertenecía a la provincia de los Guambos. Al respecto detalla: «Tierra no fría y en partes bien templada, rica y abundante en frutas y demás comidas» (p. 88).

En la época de la emancipación repúblicana, con la creación del departamento de Cajamarca (1855), Huambos se desliga del obispado de Trujillo y se integra a la provincia de Chota como distrito, mediante Ley $\mathrm{N}^{\circ} 12301$ (1857), participando destacadamente en la independencia del Perú. Años después (1882), huambinos, chotanos y cutervinos combaten contra el invasor chileno en la Guerra del Pacífico. La loma de «La Pregonada», es el símbolo del grito guerrero de los huambinos. Cuenta la historia que una treja mujer huambina arengaba a las huestes patriotas, las mismas que lograron ahuyentar al invasor y finalmente derrotarlo en la ciudad de Chota y el Miracosta (Neira, 2012; Osorio, 2019).

La cultura de la ruta turística Señorío de los Huambos se expresa en las tradicionales corridas de toros. Las ciudades de Huambos, Chota, Cutervo, Llama, Lajas, Tacabamba, Santa Cruz, Bambamarca, Celendín, Sucre y Matara tienen hermosas y monumentales plazas de toros donde se realizan grandes corridas. Estas costumbres se desarrollan dentro de las festividades de San Juan Bautista y la Virgen María, corazón de la cultura cristiana de estos pueblos (Neira, 2012; Osorio, 2019).

En cuanto a la ecología de la ruta turística Señorío de los Huambos, Raimondi y el sabio Von Humboldt (en el siglo XIX), recorrieron estas tierras dejando inventario de su rica y variada ecología. Visitaron el bosque de 
protección de Pagaibamba (Querocoto) y la reserva natural de aguas termomedicinales de Chancaybaños (Santa Cruz). En el mirador Aparíc encontraron una especie rara de orquídea, de color violeta y amarillo (Marreros, 2004). Esta ruta tiene un territorio variado y accidentado, un clima cálido y un verdor impresionante por lo fertil de sus suelos (Instituto Geológico Minero y Metalúrgico - IGMyM, 2007).

\section{Sistema de información y visitas guiadas}

Es fundamental porque permite definir la ruta a visitar, las etapas y puntos de interés del turista. La ruta turística Señorío de los Huambos, a lo largo de sus cuatro corredores, cuenta con un gran número de jóvenes conocedores de los lugares y atractivos turísticos (como es el caso de A.C.E.R. «Montaña»). Los nativos del lugar conocen al detalle cada rincón y cada atractivo de la ruta. La propuesta busca organizar a los jóvenes, capacitarlos como guías y en comunicación estratégica e idiomas para que peudan brindar un buen servicio al turista. Lo que repercute en el desarrollo de la juventud de las zonas rurales marcadas por la pobreza, evitando así la migración de los jóvenes. El sistema de información debe ser integral, mediante boletines, oficinas, de viva voz y las redes sociales (Omaña, 2017; Osorio, 2019).

\section{Sistema de microcrédito}

La implementación de servicios turísticos implica una inversión por parte del poblador, que por su condición de campesino, no cuenta con el presupuesto suficiente. Es necesaria una gestión de financiamiento, mediante microcréditos dirigido al desarrollo del turismo. Dicha gestión, favorece a los pobladores, permitiéndoles iniciar un trabajo remunerado gracias al servicio del turismo. Se puede ofrecer servicios de alojamiento, alimentación, guía, cabalgata, souvenirs, etc. Los microcréditos solicitados a las entidades bancarias pueden amortizarse y cancelar gracias al flujo turístico. Es un impulso para las iniciativas de calidad y generación de ingresos en las comunidades, como es el caso de Chimborazo en Ecuador, Cusco en Perú y el Lago Titicaca en Bolivia (Fundación CODESPA, 2011, p. 17). 


\section{Turismo de aventura: cabalgata o caminata}

Los accidentados caminos y vías de acceso de la ruta turística Señorío de los Huambos son muy adecuados para desarrollar el turismo de aventura. Existen tramos que necesariamente tienen que realizarse mediante caminata o cabalgata. Esta modalidad de acercamiento a los lugares y atractivos turísticos lo pueden organizar las comunidades más cercanas, teniendo la prioridad para ofrecer de modo ordenado y eficiente el servicio de guías y caballos para senderos cortos (Asociación Peruana de Turismo de Aventura, Ecoturismo y Turismo Especializado - APTAE, 2019). La ecología, el clima agradable y los paisajes impresionantes brindan al turista satisfacción y bienestar durante su visita. Imaginamos, por ejemplo, las caminatas o cabalgatas que se pueden realizar al visitar las grutas de los Guacharos, la cordillera de Tarros, las cataratas del Pilco, los atractivos naturales y arqueológicos de Pacopampa, las ruinas arqueológicas de Incahuasi, los caminos del inca de las montañas de Huambos, los restos arqueológicos de Sexi, Chetilla y Chiguirip, los paisajes naturales de Tacabamba y Anguía, los baños termales de Chancaybaños, etc. (BIDUNESCO, 2006; Osorio, 2019).

\section{El desarrollo de la gastronomía local}

Johan Leuridan Huys, galardonado como el mejor editor de libros de gastronomía en los Gourmand World Cookbook Awards, tiene la convicción que nuestra «riqueza culinaria es tan grande como el Perú [...] en América del Sur, Perú es el único país con arte para la cocina» (como se citó en Palacios, 2018).

La gastronomía peruana ofrece una alimentación natural y nutritiva que mejora la calidad de vida; y también, fortalece y promueve el sistema productivo local. Es una oportunidad para revalorar e innovar los cultivos tradicionales de papa nativa, oca, olluco, mashua, quinua, tarwi y otros productos pertenecientes al potencial agrícola de las comunidades rurales de la ruta turística Señorío de los Huambos (Graziano, 2010). Por ello, es necesario darle valor económico y cultural a la gran variedad gastronómica peruana (Becerra, 2010; Lauer, 2010; Olivas, 1995; Villanueva, 2010). 
La ruta turística Señorío de los Huambos es una zona verdaderamente rica en recursos alimentarios y gastronómicos. La variedad de vegetales y carnes permite la preparación de exquisitos platos: cuy con papas, cuy con vituca, chochoca con gallina, caldo de gallina, sancocho de calashto con racachas y repollo, caldo verde, pepián, caldo de mote, chicharrón con mote, shurumbo, humitas y tamales. Lo completan, el postre y las bebidas de la zona (INEI, 2010; Osorio, 2019).

\section{Desarrollo de un sistema de hospedaje vivencial}

El hospedaje vivencial es una alternativa para realizar actividades diferentes a las que se pueden experimentar en un hotel $u$ hospedaje, con lujo y confort, no obstante, igual de interesante. La ruta turística Señorío de los Huambos es un escenario óptimo, reconocida por su hospitalidad y vocación de servicio que permiten nuevas experiencias de convivencia (Pérez, 2009). Consiste en preparar una o dos habitaciones con todas sus comodidades, acompañar al turista en su descanso, atender sus necesidades básicas, crear un ambiente de diálogo, así como ayudar al turista para que las visitas a los lugares de la ruta sean satisfactorias. La idea es que el hospedaje se construya o habilite con materiales típicos de la localidad, que tenga ambientes adecuados y cómodos, con teléfono, internet, buena ventilación y vista a los imprecionantes paisajes de la zona (Mateo, 2011).

\section{Desarrollo de un sistema de seguridad integral}

El turista es un forastero y desconocido en tierras lejanas, por lo tanto, vulnerable frente a los problemas de inseguridad. Es un elemento importante para el desarrollo no solo del sistema turístico sino de la población y los diversos negocios. Si el turista paga por visitar la ruta debe contar con las condiciones de seguridad necesarias. Las rondas campesinas, organización social autónoma y democrática, son reconocidas por su gran aporte a la seguridad y pacificación del país (SUNARP, 2017). El objetivo es integrar el trabajo de la policía con el de las rondas campesinas y urbanas en el desarrollo local, la seguridad, la moral, la justicia, la paz y la tranquilidad social, colaborando en la solución de conflictos (Cacho, 2016). Por tal razón, este servicio debe ser reconocido y remunerado, de acuerdo a las ganancias que provienen del turismo (Chillihuani, 2012; Osorio, 2019). 


\section{Promoción de productos locales}

El turismo, en la perspectiva del desarrollo económico local, debe aprovechar la oportunidad para desarrollar, productos turísticos competitivos de calidad. La dura competencia entre los destinos nacionales e internacionales obliga a las entidades locales a buscar productos de mayor calidad, nuevos y que satisfagan las expectativas del turista. La comida, la textilería y los souvenirs con motivos históricos, naturales y culturales son una prioridad en la promoción de los productos locales (Baños, 2017; Erazo, 2014). En Euroinnova Formación (2017) se aconseja utilizar las ventajas de la tecnología para promocionar y vender los diversos productos turísticos; previamente, el turista puede recibir información por Internet (Ameigeiras, 2014; Gómez, 2010; Osorio, 2019).

\section{Promoción de la Marca Perú}

La Marca Perú es un activo intangible que debe ser aprovechado para la promoción y el desarrollo de la ruta turística Señorío de los Huambos y el turismo rural comunitario, por ser un «signo que distingue al Perú de otros lugares del mundo» (Alaluna, Estrada, Fernandez, Mazanett, \& Sena, 2014, p. 15). La Marca Perú hace ver a esta ruta como un lugar predispuesto y encantador. El objetivo es llegar a ser considerado dentro de las ofertas que hace el Perú al mundo, como una ruta única y exclusiva, bajo los criterios de la Marca Perú (De la Gala, 2013). Los restos arqueológicos, la gastronomía, la experiencia de vida con las familias del norte del Perú, los atractivos históricos, naturales, culturales y su variada producción agroalimentaria de gran calidad son únicos en el mundo. El Perú tiene un «pájaro de oro» (El Huacharo), que convierte a la ruta turística Señorío de los Huambos en un destino obligado y por ende, en una fuente de riqueza única (Osorio, 2019).

\section{Promoción de un instituto superior de turismo}

La educación es agente de cambio, de actitudes y comportamientos; influye directamente en la población, los turistas, las empresas y las autoridades. El diseño de una estrategia adecuada es vital para las experiencias turísticas con mayor impacto socioeconómico y ambiental. La creación de un instituto superior de turismo es prioritario, tanto para la inclusión 
sociocultural de la juventud, como para optimizar la gestión de la ruta turística Señorío de los Huambos. Por ello, se presenta como una opción para los jóvenes, con el objetivo que estudien y trabajen en la zona, contribuyendo de ese modo al desarrollo de sus pueblos, evitando la migración y el abandono de sus comunidades. Una nueva generación de profesionales puede coadyuvar a mejorar la atención de turistas y concientizar a los habitantes en el cuidado y conservación del ambiente, frente a la depredación de la flora y fauna. De manera más crítica afecta la minería ilegal, que es un foco de contaminación ambiental y guarida para la trata de personas (Osorio, 2019; Ramos \& Fernández, 2013).

\section{El Turismo Rural Comunitario (TRC)}

\section{Aproximaciones conceptuales}

El turismo es considerado como un gran generador de empleo y desarrollo socioeconómico de los países y sus comunidades que buscan una mejor calidad de vida, en la perspectiva de servicio a los objetivos del milenio (Organización Mundial del Turismo - OMT \& Red Española del Pacto Mundial de Naciones Unidas - REPMNU, 2016). En este sentido, «movilizar nuevos recursos nacionales, en cooperación con entidades financieras para fomentar el desarrollo de programas de gestión en las comunidades, se hace cada vez más necesario» (Fundación UADE, 2009, p. 6). Esta gestión promueve la cooperación de las pequeñas, medianas y grandes empresas turísticas (nacionales e internacionales), actuando con criterio de sostenibilidad y responsabilidad social frente al desarrollo de las comunidades locales. Aumentar el nivel de empleo de los pobres, potenciar el suministro de bienes y servicios, desarrollar emprendimiento turísticos, son estrategias de esta gestión (Osorio, 2019).

El TRC, innovación turística mundial, se caracteriza por promover el turismo cultural, alternativo, verde, responsable, el agroturismo o ecoturismo y la sensibilidad medioambiental. El término comunitario se refiere a la actividad turística, en un contexto de convivencia con las comunidades nativas, caracterizada por sus rasgos culturales propios. Esta actividad se vuelve sostenible y competitiva cuando permite el desarrollo cultural, combate la pobreza extrema y promueve el crecimiento económico con inclusión social 
de las comunidades en riesgo de exclusión. Por tales razones, países como Bolivia, Colombia, Costa Rica, Ecuador, México y Perú ven en este modelo una alternativa de desarrollo muy importante (De los Angeles, 2017; OMTREPMNU, 2016)

Para la OMT y REPMNU (2016) el emprendimiento del TRC, aprovechando las condiciones geográficas, climáticas, ecosistemas y culturas, hace más atractivo el turismo, identificándose así una oportunidad de negocio y una nueva forma de atender la demanda del turismo. Por su parte, Sucuy (2017) y De los Angeles (2017) promueven esta actividad por ser muy provechosa para luchar contra el estrés, efecto de la vida urbana. El encuentro con áreas naturales, las caminatas, los campamentos, las excursiones, los paseos a caballo y el canotaje son actividades recomendadas para combatir el estrés.

En el Perú, el TRC se desarrolla de manera planificada y sostenible en diversas comunidades rurales del país. Se basa en la participación de las poblaciones rurales (locales) organizadas, con el propósito de alcanzar su propio beneficio en función de su propia cultura e idiosincrasia (MINCETUR, 2017, p. 56). Los 40 destinos del TRC, cada uno de ellos con varios emprendimientos y distintos grados de desarrollo, centran su atención en la participación de las comunidades rurales (locales), la sostenibilidad de la actividad turística y la inclusión socioeconómica de las mismas poblaciones (OMT y REPMNU, 2016). El Proyecto Turural y el Programa Nacional de TRC promueven diversos productos y servicios turísticos, usando adecuadamente sus activos naturales, culturales y humanos (MINCETUR, 2017).

Sepúlveda, Basurto y Vizcarra (2010), en la línea de los emprendimientos innovadores, resaltan la experiencia del TRC en la región Cusco y proponen un plan estratégico para su desarrollo basado en las siguientes acciones: priorizar la implementación del TRC, acorde con la evolución de la demanda y preferencias turísticas a nivel mundial; diseñar una variedad de ofertas turísticas dirigidas, tanto a la satisfacción de la demanda como al desarrollo de las comunidades locales; promover la creación de agencias de turismo y diseño de paquetes turísticos en función de los lugares más conocidos y destacados por sus atractivos turísticos; crear asociaciones para facilitar la organización, planeamiento de estrategias y objetivos frente a las necesidad urgentes; difundir los productos, priorizando la vivencia cultural, el 
medioambiente, los atractivos turísticos del lugar en relación con la vivencia personal del turista en la comunidad; implementar, métodos de control para evitar la aculturación, la contaminación del medioambiente y promover la competitividad de las comunidades receptoras o de destino; desarrollar iniciativas con posibilidades de éxito, usando una gestión estratégica e integradora, optimización del potencial turístico, la infraestructura, el capital humano, los recursos financieros, la relevancia social y los recursos culturales y ambientales, en cada una de sus fases de implementación; desarrollar un trabajo coordinado con las agencias de viaje, alojamientos, restaurantes, entidades gubernamentales y comunidades implicadas en el emprendimiento; crear una infraestructura adecuada, con accesos, servicios de sanidad, seguridad, comunicaciones, educación e informática, etc.; implementar el acceso a las tecnologías de la comunicación para la promoción de los emprendimientos y mercadeo de sus productos en el mercado nacional y mundial.

\section{Dimensiones del turismo rural comunitario}

\section{Lo auténtico: nuevas experiencias históricas, culturales, ambientales autóctonas}

Lévano (2016), sostiene que la actividad turística mundial se caracteriza por su nueva tendencia: la búsqueda de nuevas experiencias, mayor contacto con la naturaleza, la vida de los espacios rurales, naturales y culturales autóctonos. «Esta nueva tendencia, ha originado una creciente valoración por lo auténtico, la búsqueda de lo natural y lo sostenible, en donde, el entorno no urbano, se vuelve el principal protagonista» (Cruz, 2011, p. 32). Esta búsqueda se encuentra en el TRC, alternativa que permite al turista y a la comunidad encontrarse en el quehacer de sus labores diarias, en el aprendizaje de las costumbres y la interrelación cultural (Osorio, 2019).

\section{Atractivos naturales y culturales, rurales}

Lévano (2016, p. 9) sostiene:

Los atractivos naturales y culturales se relacionan con, la búsqueda de lo natural y lo sostenible, en el sentido que generen una creciente valoración por lo auténtico, donde el entorno no urbano, con sus riquezas naturales y culturales, se vuelve el principal protagonista. 
Toda la ruta turística Señorío de los Huambos esta llena de estos atractivos: montañas, ríos, lagunas, cataratas, cavernas o grutas, flora y fauna, monumentos arqueológicos de diversas épocas y su gran variedad de producción de recursos naturales y culturales, etc. Pero sobre todo, un encuentro directo con cada persona, su mundo y su visión del mundo. Nuevas experiencias que permitirán al nuevo viajero un mejor contacto con los espacios rurales y culturales de cada lugar, de cada pueblo (Cruz, 2011; Osorio, 2019).

\section{Atractivos turísticos y servicios complementarios}

La ruta turística Señorío de los Huambos tiene una variedad de atractivos turísticos y servicios complementarios, muchos de ellos aún no descubiertos o explotados eficientemente. Las actividades recreativas no convencionales, el conocimiento de experiencias y vivencias distintas, la convivencia con las comunidades locales, la participación en el deporte local, los nuevos enfoques de la salud, las nuevas experiencias gastronómicas y el encuentro con nuevas formas culturales son un extraordinario abanico de opciones o servicios complementarios. Los deportes de aventura como el parapente, el paracaidismo, la escalada, el senderismo, el puenting, el canotaje, kayak y ciclismo, ya son toda una experiencia en diversos lugares de la ruta. Estar cerca del fogón, experimentar el poder curativo de las hierbas, la naturaleza, las flores, los frutos y plantas medicinales, son también servicios complementarios de gran valor para el turista (Cruz, 2016; Sariego, Pons, \& Serrano, 2016).

\section{Inclusión económica y desarrollo social de las comunidades rurales}

La OMT y REPMNU (2016) enfatizan «la importancia de impulsar el TRC, en las Américas, con el fin de combatir la pobreza extrema y promover el crecimiento económico con inclusión social» (p. 13). Los grandes descubrimientos de restos arqueológicos milenarios de Lambayeque, Pacopampa, y ahora en Cutervo el Señor del Ilucán, las grutas de los Guacharos, son solo parte de la inagotable riqueza con la que cuenta el norte peruano, que junto a la diversidad de su producción agropecuaria y medioambiental, son un potencial de desarrollo económico y social. Comprometer a las comunidades rurales, detener la migración de los 
jóvenes, proponer alternativas educativas y laborales dentro de las actividades del turismo, permite poner en valor los propios recursos turísticos, naturales y gastronómicos. Son grandes prioridades (Osorio, 2019; Sariego et al., 2016).

\section{Recuperación de las zonas rurales en riesgo de exclusión}

El TRC es una prioridad para la transformación de las zonas rurales en riesgo de exclusión. Los territorios que comprenden la ruta turística Señorío de los Huambos, viven aún una situación de exclusión desde hace décadas. El atraso y el subdesarrollo se observan por todas partes. Las zonas rurales son muy ricas en historia, cultura y productos naturales, pero paradogicamente no cuentan con pistas, servicios públicos básicos, planes de desarrollo, etc. El TRC genera beneficios para el territorio local, activando la economía local, las actividades productivas, el comercio, etc., además de reducir la migración de la juventud, frenar el despoblamiento de las zonas rurales, reactivar la cultura, la educación, el trabajo y el desarrollo sostenible mediante el turismo (Osorio, 2019; Sariego et al., 2016).

\section{Comunidades rurales organizadas y gestión de los servicios y su desarrollo}

El TRC prioriza la participación directa de la población de una comunidad en la gestión de los servicios que brinda esta actividad económica, en la que la población tiene una participación directa y libre. En ese sentido, cada comunidad es una organización responsables, capaz de llevar a cabo la coordinación, planificación y ejecución de actividades turísticas de su comunidad. El Programa Nacional de TRC articula emprendimientos planificados, que se deben aprovechar para recibir en mejores condiciones al turistas, promover el desarrollo económico local y efectivizar la reducción de la pobreza (Osorio, 2019; Sariego et al., 2016).

\section{La estadía en comunidades rurales}

La Fundación CODESPA (2011) sostiene que el TRC es una actividad vivencial, que tiene por objetivo la estadía en comunidades ubicadas en el medio rural. En la misma perspectiva, Cruz (2016) afirma que la estadía permite el acercamiento del turista a la historia y la cultural de cada pueblo. 
La vida de las comunidades rurales son de gran interés y motivación para el hombre urbano, el turista que no solo busca conocer, sino huir del estrés, adquirir mayor concientización del medio natural y enriquecer su intelecto con las manifestaciones culturales, artísticas y arqueológicas. Son un espacio de convivencia, que permite al turista una experiencia más humana, de encuentro y diálogo entre personas de culturas distintas (Osorio, 2019).

Toda la ruta turística Señorío de los Huambos, a lo largo de sus cuatro corredores, es una cadena de oportunidades, de encuentro con la naturaleza, la historia y la cultura de cada pueblo, y también, con distintas personas. El buen trato recibido, la hospitalidad y amabilidad de su gente jamás son olvidados. En este ambiente, el turista puede involucrarse en actividades cotidianas como la siembra, la molienda, la cosecha, el ordeño de vacas, el pelachancho, etc. Las visitas y el baño en las lagunas o chorreras naturales, las caminatas, las cabalgatas, las tardes de fulbito, etc., son actividades que divierten e integran. Las visitas a las áreas naturales, paisajes, flora y fauna silvestre permiten apreciar, disfrutar y estudiar los fenómenos naturales. Mientras que la estadía organizada crea convivencia y al mismo tiempo compromiso con la conservación y cuidado del ambiente y la cultura local, al mismo tiempo, evita actividades ilegales como la tala indiscriminada, la caza de aves en peligro de extinción, el huaqueo y la minería informal (Osorio, 2019).

\section{Fortalecimiento de la identidad local de las áreas rurales}

Las comunidades rurales, moradas de grupos humanos, son hoy en día la fuente del sustento de las mismas comunidades. Su territorio y sus recursos, diferentes en cada comunidad, determinan las actividades económicas y el desarrollo de la comunidad. Un elemento indispensable de estas comunidades es su propia identidad. Si se pierde la identidad territorial, las comunidades rurales o pueblos originarios quedan condenados a desaparecer. La tarea es recuperar y fortalecer tal identidad y contribuir de ese modo a su propio desarrollo. Esa es la perspectiva de la ruta turística Señorío de los Huambos y del TRC, gran oportunidad de desarrollo de su identidad, equilibrio territorial y económico (Cruz, 2011; Osorio, 2019; Sariego et al., 2016). 


\section{Método}

\section{Diseño}

Es una investigación básica de diseño correlacional transversal, descriptivo explicativo, con enfoque cualitativo (Hernández, 2014).

\section{Participantes}

Como población de la investigación se comprendió a todos los habitantes de las comunidades ubicadas en los cuatro corredores de la ruta turística Señorío de los Huambos. Considerando el tamaño de la población, se decidió seleccionar una muestra significativa y proporcional, aplicando un muestreo no probabilístico intencionado, donde los investigadores determinan el tamaño de la muestra, según los criterios de selección aleatoria, intereses y libre participación de los participantes (Hernández, 2014). Luego, la muestra quedó conformada por 120 participantes (30 de cada corredor turístico de la ruta turística Señorío de los Huambos): líderes de la comunidad, ronderos, transportistas, dueños de hoteles y restaurantes, guías de turismo (Osorio, 2019).

\section{Instrumento}

Se seleccionó las técnicas de la encuesta estructurada y la observación de evidencias. Como instrumento se diseñó un cuestionario de 152 ítems o preguntas, con alternativas de respuestas múltiples. Según la escala de Likert: Nunca (1) Muy pocas veces (2), Muchas veces (3), Casi siempre (4) y Siempre (5). Además, una ficha de observación y registro de datos.

La validación del instrumento se realizó mediante la técnica de juicio de cinco expertos (con grado de doctor). El resultado del análisis mediante la prueba estadística alfa de Cronbach (.930) demuestra que el instrumento tiene una confiabilidad de nivel alto (Murphy \& Davidshofer, 1988). 


\section{Procedimiento}

Se delimitó el proyecto de investigación: definición del problema, estructuración del marco teórico y diseño de las variables ruta turística Señorío de los Huambos (10 dimensiones) y TRC (8 dimensiones).

Para el procesamiento, sistematización, análisis e interpretación de los datos se utilizaron las diversas mediciones del programa estadístico SPSS. Dichos datos fueron analizados en función de los objetivos e hipótesis, mediante las pruebas coeficiente de correlación de Spearman y la prueba de normalidad de Kolmogorov-Smirnov.

\section{Resultados}

Los resultados se presentan mediante cuadros univariados o bivariados (Osorio, 2019).

En la Tabla 5 se presentan los resultados de la prueba de normalidad de cada variable del estudio. Para la ruta turística Señorío de los Huambos el estadístico de Kolmogorov Smirnov es .263, con una probabilidad de .000 $(<.05)$; se confirma, por lo tanto, la hipótesis que señala que existe una relación significativa entre la ruta turística Señorío de los Huambos y el TRC, ya que los puntajes no tienen distribución normal. En el caso del TRC el resultado es .381 , con una probabilidad de error igual a $.000(<.05)$, se confirma también la hipótesis, ya que los puntajes no tienen distribución normal. Por lo tanto, entre la ruta turística Señorío de los Huambos y el TRC existe una relación altamente significativa.

\section{Tabla 5}

Prueba de normalidad de la ruta turística Señorío de los Huambos (RTSH) y el turismo rural comunitario (TRC)

\begin{tabular}{lccc}
\hline & \multicolumn{3}{c}{ Kolmogorov-Smirnov } \\
\cline { 2 - 4 } & Estadístico & gl & $p$ \\
\hline RTSH & .263 & 120 & .000 \\
TRC & .381 & 120 & .000 \\
\hline
\end{tabular}




\section{Resultados por objetivos según el coeficiente de correlación de Spearman}

Según el coeficiente de correlación de Spearman el resultado es de .568, con probabilidad de $.000(<.01)$; se confirma la hipótesis, es decir, existe relación significativa entre la ruta turística Señorío de los Huambos y el TRC. El coeficiente positivo demuestra una relación directa entre las variables, donde a mayor puntaje para la ruta turística Señorío de los Huambos, mayor es el puntaje para TRC (Tabla 6). Por consiguiente, se evidencia una necesidad de interés nacional y regional que busca una urgente solución.

\section{Tabla 6}

Coeficiente de correlación de Spearman entre la ruta turística Señorío de los Huambos (RTSH) y el turismo rural comunitario (TRC)

\begin{tabular}{lllcc}
\hline & & RTSH & TRC \\
\hline \multirow{3}{*}{$\begin{array}{c}\text { Rho de } \\
\text { Spearman }\end{array}$} & RTSH & Coeficiente de correlación & 1.000 & $.568^{* *}$ \\
& & $\mathrm{~N}$ & - & .000 \\
& & & 120 & 120 \\
& & & $.568^{* *}$ & 1.000 \\
& \multirow{2}{*}{ TRC } & Sig. (bilateral) & .000 & - \\
& & $\mathrm{N}$ & 120 & 120 \\
\hline
\end{tabular}

Nota: ${ }^{* *}$ La correlación es significativa al nivel .01 (bilateral).

En la Tabla 7 se puede observar que nueve de las correlaciones presentan una alta significancia; seis con significancia moderada, con tendencia a alta; y dos,con significancia baja, con tendencia a moderada. 


\section{Tabla 7}

Correlaciones específicas entre la ruta turística Señorío de los Huambos (RTSH) y el turismo rural comunitario (TRC)

\section{Correlación de dimesiones}

Sperman

.557

1. RTSH y la valoración por lo auténtico: nuevas experiencias históricas, culturales, ambientales y autóctonos.

2. RTSH y el mayor contacto con los atractivos naturales y culturales rurales.

3. La RTSH y la variedad de atractivos turísticos y servicios complementarios.

4. RTSH y la generación económica e inclusión social de las poblaciones rurales.

5. La RTSH y la transformación inclusiva de las zonas rurales, en riesgo de exclusión.

6. RTSH y la participación directa de las comunidades locales, organizadas en la gestión del servicio y su desarrollo.

7. La RTSH y la estadía en comunidades locales ubicadas en el medio rural.

8. RTSH y el desarrollo de las áreas rurales y fortalecimiento de la identidad local.

9. La revalorización cultural, histórica y ecológica y el TRC.

10. El sistema de información y visitas guiadas y el TRC.

11. El sistema de microcrédito y el TRC.

12. El turismo de aventura: cabalgata o caminata y el TRC.

13. La gastronomía local y el TRC.

14. El sistema de hospedaje vivencial y el TRC.

15. El sistema de seguridad integral y el TRC.

16. La promoción de productos locales y el TRC.

17. La promoción de la Marca Perú y TRC.

18. La promoción de un instituto superior de turismo para la formación de sus agentes locales y el TRC.
.415

.477

.261

.265

.311

.346

.368

.341

.507

.552

.413

.592

.569

.527

.535

.569

.552
Significancia

(Cohen, 1989)
Probabilidad

$.000(<.01)$

Alta

$.000(<.01) \quad$ Moderada - Alta

$.000(<.01) \quad$ Moderada - Alta

$.000(<.01) \quad$ Baja - Moderada

$.000(<.01) \quad$ Baja - Moderada

$.000(<.01) \quad$ Moderada - Alta

$.000(<.01) \quad$ Moderada - Alta

$.000(<.01) \quad$ Moderada - Alta

$.000(<.01) \quad$ Moderada - Alta

$.000(<.01) \quad$ Alta

$.000(<.01) \quad$ Alta

$.000(<.01) \quad$ Moderada - Alta

$.000(<.01)$

Alta

$.000(<.01)$

Alta

$.000(<.01)$

Alta

Alta

Alta

$.000(<.01)$

Alta

Nota: ${ }^{* *}$ La correlación es significativa al nivel .01 (bilateral). 


\section{Tabla 8}

Registro de observación: evidencias de recursos turísticos (históricos, naturales y culturales) de la ruta turística Señorío de los Huambos

\begin{tabular}{|c|c|c|c|}
\hline \multicolumn{4}{|c|}{ CORREDOR TURÍSTICO HUAMBOS (H) } \\
\hline Lugar Turístico (LT) & Altitud (m s. n. m.) & Temperatura $\left({ }^{\circ} \mathrm{C}\right)$ & Distancia (H - LT) \\
\hline Iglesia matriz San Juan Bautista de Huambo & 2276 m s. n. m. & $21^{\circ} \mathrm{C}$ & $0 \mathrm{~km}$ \\
\hline Mirador el Aparíc & 2290 m s. n. m. & $18^{\circ} \mathrm{C}$ & $0 \mathrm{~km}$ \\
\hline Camino inca la Capilla & 2295 m s. n. m. & $18^{\circ} \mathrm{C}$ & $0.5 \mathrm{~km}$ \\
\hline Camino inca Chentén & 2295 m s. n. m. & $15^{\circ} \mathrm{C}$ & $0.5 \mathrm{~km}$ \\
\hline Caminos prehispánicos - Pencapuquio & 2200 m s. n. m. & $23^{\circ} \mathrm{C}$ & $0.1 \mathrm{~km}$ \\
\hline Gruta el Talegón & 2270 m s. n. m. & $23^{\circ} \mathrm{C}$ & $1.5 \mathrm{~km}$ \\
\hline Catarata la Toma & 2250 m s. n. m. & $23^{\circ} \mathrm{C}$ & $1.5 \mathrm{~km}$ \\
\hline Restos fósiles Antivoloma & 2245 m s. n. m. & $20^{\circ} \mathrm{C}$ & $1.5 \mathrm{~km}$ \\
\hline Monumentos arqueológicos & Gastronomía & $\begin{array}{l}\text { Costumbres y } \\
\text { tradiciones }\end{array}$ & $\begin{array}{c}\text { Comunidades para el } \\
\text { TRC }\end{array}$ \\
\hline $\begin{array}{c}\text { Guanbo tanbo real inca, } \\
\text { Conjunto arqueológico Incahuasi } \\
\text { y sitio arqueológico la Unión } \\
\text { y Chococirca }\end{array}$ & $\begin{array}{l}\text { Cuy con papas, } \\
\text { chicharron con mote, } \\
\text { dulce chipche con leche y } \\
\text { caldo verde de payco }\end{array}$ & $\begin{array}{l}\text { Bajada de Reyes, } \\
\text { carnavales, } \\
\text { Semana Santa y } \\
\text { Día de los muertos }\end{array}$ & $\begin{array}{c}\text { Huambos, } \\
\text { Querocoto, } \\
\text { y Querocotillo }\end{array}$ \\
\hline Hospedajes: 15 & Restaurantes: 12 & Fotos: 160, Videos: 2 & Documentos: 20 \\
\hline \multicolumn{4}{|c|}{ CORREDOR TURÍSTICO CHOTA (CH) } \\
\hline Lugar Turístico (LT) & Altitud (m s. n. m.) & Temperatura $\left({ }^{\circ} \mathrm{C}\right)$ & Distancia (H - LT) \\
\hline Plaza de toros El Vizcaino & 2388 m s. n. m. & $16-25^{\circ} \mathrm{C}$ & $3 \mathrm{~km}$ \\
\hline Parque El Rondero & 2388 m s. n. m. & $16-25^{\circ} \mathrm{C}$ & $5 \mathrm{~km}$ \\
\hline Valle del Tuctuhuasi & 2350 m s. n. m. & $16-25^{\circ} \mathrm{C}$ & $6 \mathrm{~km}$ \\
\hline Gruta de Negropampa & 2400 m s. n. m. & $20^{\circ} \mathrm{C}$ & $7 \mathrm{~km}$ \\
\hline Santuario Chucumaca (8 km) & 2500 m s. n. m. & $15^{\circ} \mathrm{C}$ & $12 \mathrm{~km}$ \\
\hline Catarata Vizcamayo o Guerrero de Mayo & 2450 m s. n. m. & $16^{\circ} \mathrm{C}$ & $8 \mathrm{~km}$ \\
\hline Grutas de Chul-chul & 2480 m s. n. m. & $18^{\circ} \mathrm{C}$ & $8 \mathrm{~km}$ \\
\hline Nacimiento río Conchano & 2370 m s. n. m. & $21^{\circ} \mathrm{C}$ & $9 \mathrm{~km}$ \\
\hline Torres de Chiguirip & 2300 m s. n. m. & $25^{\circ} \mathrm{C}$ & \\
\hline Monumentos arqueológicos & Gastronomía & $\begin{array}{l}\text { Costumbres y } \\
\text { tradiciones }\end{array}$ & $\begin{array}{c}\text { Comunidades para el } \\
\text { TRC }\end{array}$ \\
\hline $\begin{array}{l}\text { Chullpas de Chetilla, chullpas de } \\
\text { Churucancha, sitio arqueológico de } \\
\text { Segues, sitio arqueológico de } \\
\text { Pacopampa, Chullpas de Chetillas } \\
\text { y la Torre y los gemelos de } \\
\text { la Paccha. }\end{array}$ & $\begin{array}{l}\text { Cuy con papas, chupe o caldo } \\
\text { verde con huevo, sopa de } \\
\text { chochoca, tamales de } \\
\text { chancho, pepián de gallina, } \\
\text { chicharrón con mote y humitas. } \\
2649 \text { m s. n. m. }\end{array}$ & $\begin{array}{c}\text { Feria taurina de } \\
\text { San Juan, } \\
\text { Arte textil popular, } \\
\text { carnavales, el bota luto, } \\
\text { el corta pelo, la lava y la } \\
\text { yunza. }\end{array}$ & $\begin{array}{l}\text { Cuyumalca, Conchan, } \\
\text { Chuguirip, Chetilla, } \\
\text { Lajas, Tacabamba, } \\
\text { Anguía, Chalamarca, } \\
\text { Pacha, Chadin. }\end{array}$ \\
\hline Hospedajes: 60 & Restaurantes: 55 & Fotos: 180, Videos: 3 & Documentos: 15 \\
\hline
\end{tabular}




\begin{tabular}{|c|c|c|c|}
\hline \multicolumn{4}{|c|}{ CORREDOR TURÍSTICO CUTERVO (C) } \\
\hline Lugar Turístico (LT) & Altitud (m s. n. m.) & Temperatura $\left({ }^{\circ} \mathrm{C}\right)$ & Distancia (H - LT) \\
\hline Catedral de Cutervo & & $13-25^{\circ} \mathrm{C}$ & $0 \mathrm{~km}$ \\
\hline Museo Carlos Alberto Sánchez García & 2.655 m s. n.m. & $13-25^{\circ} \mathrm{C}$ & $2 \mathrm{~km}$ \\
\hline Mirador del llucán & 2.656 m s. n. m. & $13-25^{\circ} \mathrm{C}$ & $5 \mathrm{~km}$ \\
\hline Blanco Arenal & 2.620 m s. n. m. & $15-25^{\circ} \mathrm{C}$ & $5 \mathrm{~km}$ \\
\hline Torres de Rejopampa & 2.650 m s. n. m. & $18^{\circ} \mathrm{C}$ & $8 \mathrm{~km}$ \\
\hline Cuevas de Huichud & 2.650 m s. n. m. & $17^{\circ} \mathrm{C}$ & $8 \mathrm{~km}$ \\
\hline Cuevas y grutas de Rodiopampa & 2.620 m s. n. m. & $15^{\circ} \mathrm{C}$ & $8 \mathrm{~km}$ \\
\hline Parque Nacional de Cutervo & $2.200-2.500$ m s. n. m. & $13-5^{0} \mathrm{C}$ & $15 \mathrm{~km}$ \\
\hline Catarata y laguna Pilco & 2.300 m s. n. m. & $16^{\circ} \mathrm{C}$ & $12 \mathrm{~km}$ \\
\hline Monumentos arqueológicos & Gastronomía & $\begin{array}{l}\text { Costumbres y } \\
\text { tradiciones }\end{array}$ & $\begin{array}{c}\text { Comunidades para el } \\
\text { TRC }\end{array}$ \\
\hline $\begin{array}{l}\text { El Señor del Ilucán, } \\
\text { Pinturas rupestres las Hualingas, } \\
\text { sitio arqueológico Las iglesias, } \\
\text { ruinas inca el Paratón, } \\
\text { Chullpas de Llipa. }\end{array}$ & $\begin{array}{l}\text { Cuy frito con papas, } \\
\text { caldo verde, caldo de gallina, } \\
\text { sopa de chochoca, sopa de } \\
\text { shurumbo, tamales y humitas, } \\
\text { chicharrón con mote, sancochado. }\end{array}$ & $\begin{array}{l}\text { Festividad de San Juan } \\
\text { Bautista, Semana Santa } \\
\text { Landaruto, el Pararaico, } \\
\text { etc. }\end{array}$ & $\begin{array}{l}\text { Cutervo, Sócota, } \\
\text { Callayuc, Santa Cruz de } \\
\text { Cutervo, San Andrés, } \\
\text { Santo Tomás, } \\
\text { La Ramada. }\end{array}$ \\
\hline Hospedajes: 45 & Restaurantes: 25 & Fotos: 165,Videos: 9 & Documentos: 12 \\
\hline \multicolumn{4}{|c|}{ CORREDOR TURÍSTICO SANTA CRUZ (SC) } \\
\hline Lugar Turístico (LT) & Altitud (m s. n. m.) & Temperatura $\left({ }^{\circ} \mathrm{C}\right)$ & Distancia (H - LT) \\
\hline Museo Royma & 2.035 m s. n. m. & $18-26^{\circ} \mathrm{C}$ & $1 \mathrm{~km}$ \\
\hline Baños termales de Chancay baños & 1.625 m s. n. m. & $20-28^{\circ} \mathrm{C}$ & $4 \mathrm{~km}$ \\
\hline $\begin{array}{l}\text { Parque paleontológico Piedra } \\
\text { Chamana de Sexi }\end{array}$ & 2.500 m s. n. m. & $18-23^{\circ} \mathrm{C}$ & $5 \mathrm{~km}$ \\
\hline Grutas de Ushcupishgo & 2.300 m s. n. m. & $13-21^{\circ} \mathrm{C}$ & $6 \mathrm{~km}$ \\
\hline Bosques nublados de Udima & 2.200 m s. n. m. & $15-21^{\circ} \mathrm{C}$ & $7 \mathrm{~km}$ \\
\hline $\begin{array}{l}\text { Pinturas rupestres las } \\
\text { Guitarras y Calvario }\end{array}$ & 2.350 m s. n. m. & $13-22^{\circ} \mathrm{C}$ & $4 \mathrm{~km}$ \\
\hline Cuevas de Uticyacu & 2.380 m s. n. m. & $13-21^{\circ} \mathrm{C}$ & $5 \mathrm{~km}$ \\
\hline Monumentos arqueológicos & Gastronomía & $\begin{array}{l}\text { Costumbres y } \\
\text { tradiciones }\end{array}$ & $\begin{array}{c}\text { Comunidades para el } \\
\text { TRC }\end{array}$ \\
\hline $\begin{array}{l}\text { Vestigios arqueológicos de Sexi, } \\
\text { sitio arqueológico Poro Poro, etc. }\end{array}$ & $\begin{array}{l}\text { Tamales y humitas, } \\
\text { chicharrón con mote, } \\
\text { cuy frito con papas, } \\
\text { caldo verde y shurumbo. }\end{array}$ & $\begin{array}{l}\text { El pararaico, bota } \\
\text { luto y la festividad San } \\
\text { Agustín de Catache. }\end{array}$ & $\begin{array}{l}\text { Santa Cruz, Chancay } \\
\text { Baños, Sexi, Catache, } \\
\text { Ninabamba y Udima. }\end{array}$ \\
\hline Hospedajes: 25 & Restaurantes: 30 & Fotos: 106,Videos: 8 & Documentos: 10 \\
\hline
\end{tabular}

Fuente: Osorio (2019). 


\section{Discusión}

Los resultados obtenidos en esta investigación tienen coherencia y relación con las experiencias exitosas de TRC, desarrolladas en Cusco, Perú (Sepúlveda et al., 2010); Lago Titicaca, Bolivia (Sariego et al., 2016), Chimborazo, Ecuador (De los Ángeles, 2017; Sucuy, 2017) y Jalisco, México (Arredondo, Hernández \& Mendoza, 2013).

La correlación entre la ruta turística Señorío de los Huambos y el TRC es positiva con una significancia alta (0.568) (Cohen, 1988). El coeficiente es positivo, demuestra una relación directa entre las variables; es decir, a mayor puntaje para la ruta turística Señorío de los Huambos, mayor es el puntaje para el TRC. Es factible la implementación de la propuesta de la ruta turística Señorío de los Huambos para el desarrollo del TRC, de allí la importancia y trascendencia de este trabajo, al ser el tema de interés nacional y regional.

Las correlaciones específicas son positivas, con significancia alta, entre la ruta turística Señorío de los Huambos y la valoración por lo auténtico: nuevas experiencias históricas, culturales, ambientales autóctonos; el TRC y el desarrollo de un sistema de información y visitas guiadas; el sistema de microcréditos; el desarrollo de la gastronomía local; el desarrollo de un sistema de hospedaje vivencial; el desarrollo del sistema de seguridad integral; la promoción de productos locales; la promoción de la Marca Perú; y, la promoción de un instituto superior de turismo para la formación de sus agentes locales. Lo que quiere decir que la ruta turística Señorío de los Huambos tiene el potencial (expresadas en la Tabla 8) para poner en marcha el desarrollo del TRC en la región Cajamarca.

Las correlaciones entre la ruta turística Señorío de los Huambos y el mayor contacto con los atractivos naturales y culturales rurales; la variedad de atractivos turísticos y servicios complementarios; la participación directa de las comunidades locales organizadas en la gestión del servicio y su desarrollo; la estadía en comunidades locales ubicadas en el medio rural; el desarrollo de las áreas rurales y fortalecimiento de la identidad local; el turismo de aventura: cabalgata o caminata, son positivas con significancia moderada, con tendencia a alta. Por lo tanto, la ruta turística Señorío de los Huambos tiene las fortalezas (expresadas en la Tabla 8) para el desarrollo del TRC en la región Cajamarca. 
Asimismo, las correlaciones entre la ruta turística Señorío de los Huambos y la generación económica e inclusión social de las poblaciones rurales y la transformación inclusiva de las zonas rurales en riesgo de exclusión son positivas con significancia baja, con tendencia a alta. Estás últimas, dependen de la implementación de las primeras.

La diferencia entre los hallazgos no significa que unos tengan mayor importancia que otros, sino más bien que, los de menor significancia, dependen de los de mayor significancia. El orden de prioridades establecido mediante los hallazgos permite proponer dar mayor énfasis en los segmentos que requieren mayor atención. Las de baja y moderada significancia dependen de la priorización de los resultados con alta significancia.

\section{Conclusiones}

Los resultados evidencian que existe un enorme potencial, altamente significativo, en la ruta turística Señorío de los Huambos, que repercute en el desarrollo del TRC en la provincia de Chota, Cutervo y Santa Cruz, región Cajamarca.

La implementación de la ruta turística Señorío de los Huambos tiene una influencia altamente significativa en la valoración por lo auténtico: nuevas experiencias históricas, culturales, ambientales autóctonas (exigencias del TRC).

Al mismo tiempo, el TRC tiene una relación altamente significativa con el desarrollo de un sistema de información y visitas guiadas, el sistema de microcréditos, el desarrollo de la gastronomía local, el desarrollo de un sistema de hospedaje vivencial, el desarrollo del sistema de seguridad integral, la promoción de productos locales, la promoción de la Marca Perú, y la implementación de un instituto superior de turismo para la formación de sus agentes locales (objetivos propuestos por la ruta turística Señorío de los Huambos).

La implementación de la ruta turística Señorío de los Huambos tiene una influencia moderada con tendencia a alta en el mayor contacto con los atractivos naturales y culturales rurales, la variedad de atractivos turísticos y 
servicios complementarios, la participación directa de las comunidades locales organizadas en la gestión del servicio y su desarrollo, la estadía en comunidades locales ubicadas en el medio rural, el desarrollo de las áreas rurales y fortalecimiento de la identidad local, y el turismo de aventura: cabalgata o caminata (exigencias del TRC).

El funcionamiento de la ruta turística Señorío de los Huambos influye positivamente en la generación económica e inclusión social de las poblaciones rurales y la transformación inclusiva de las zonas rurales en riesgo de exclusión (exigencias del TRC).

Finalmente, la evidencia de la abundancia de recursos turísticos, de carácter histórico, natural y cultural, fortalece la factibilidad de la propuesta de la ruta turística Señorío de los Huambos para el desarrollo del TRC.

\section{Referencias}

Alaluna, R. M., Estrada C. E., Fernandez, C. A., Mazanett K. P., \& Sena N. Y. (2014). Marca Perú: un signo que distingue. Lima: USMP.

Ameigeiras, C. (2014). Comercialización y venta de servicios turísticos. Madrid: Editorial Síntesis, S. A.

Asociación Peruana de Turismo de Aventura, Ecoturismo y Turismo Especializado - APTAE. (2019). Recuperado de http://aptae.pe/wp-content/uploads/2019/01/Requisitos-para-ser-miembros-de-APTAE2018.pdf

Arredondo, P., Hernández, C., \& Mendoza, T. (2013). Propuesta para el diseño de rutas turísticas culturales. El caso del sur del estado de Jalisco. Turismo \& Sociedad, 6(2), 324-344.

Baños L. (2017). Promoción y comercialización de productos y servicios turísticos locales. Madrid: educacion.es.

Becerra, K. (2010). Café de las nubes del Perú. Lima: USMP.

Betanzos, J. (1551-1880). Suma y Narración de los Incas, que los indios llamaron Capaccuna, que fueron señores de la ciudad del Cuzco y de todo lo a ella subjeto. Madrid: BNE.

BID-UNESCO (2006). El Qhapaq Ñan Camino Principal Andino. Plan de acción regional para un proceso de integración y cooperación. Lima: BID.

Cabrera, E. (2014). Lugares Turísticos de Cutervo. Cutervo: ACC.

Cacho, L. F. (2016). Mecanismos de coordinación entre la Policía Nacional del Perú y las rondas campesinas: un estudio de la política pública de seguridad ciudadana del distrito de Cajamarca, periodo 2012-2014. Lima: PUCP.

Calderón, L. (2010). Informe de los vestigios arqueológicos de Poro Poro. Carchi. Revista Virtual de Arqueología, 3(2), 175-196.

Carrera, F. (1644). La lengua yunga o mochica, según el arte. Lima: Imp. Peruana de E. Z. Casanova.

Chillihuani, V. (2012). Las rondas campesinas del Perú una alternativa de justicia en las zonas rurales alto andinas, el caso de Ocongate un distrito rural del departamento del Cusco 1992-2011. Lima: PUCP. 
Cohen, J. (1998). Quantitative methods in psychology. American Psychological Association. Psychological Bulletin, 12(1),155-159.

Cruz, F. M. (2011). Identidad territorial y el turismo vivencial. Caso departamento de Ancash. Revistas de Investigación UNMSM,15(27).

Cruz, S. (2016). Turismo alternativa de desarrollo de los pueblos y regiones del Perú. Caso: distrito de Callahuanca, provincia de Huarochiri, departamento de Lima. Lima: UNMSM.

De la Calancha, A. (1639). Crónica moralizada de la orden de San Agustín en el Perú, con sucesos ejemplares en esta monarquía. Barcelona: Cervantes Virtual. Recuperado de http://www.cervantesvirtual.com/obra/coronicamoralizada-del-orden-de-san-augustin-en-el-peru-con-sucesos-egenplares-en-esta-monarquia-l

De la Gala, F. (2013). La Marca Perú y su influencia en la generación de identidad en estudiantes universitarios de Trujillo. Trujillo: UCV.

De los Ángeles, M. (2017). Turismo rural como estrategia de desarrollo local, caso Parroquia Mulaló, Cantón Lacatunga. Riobamba: ESP Chimborazo.

Erazo, A. (2014). Adecuación e implementación del espacio físico de la oficina de información y atención al turista de la ciudad de El Ángel, provincia del Carchi. Proyecto Cantón Espejo, Carchi, Ecuador.

Eslava, L. (1985). Monografía de Cajabamba. Recuperado de http://www.cajabamba.galeon.com/ aficiones876172.html

Espinoza, W. (1967). El Primer informe Etnológico sobre Cajamarca, año de 1540. Revista Peruana de Cultura, 37. Disponible de http://biblioteca.cultura. pe:8020/cgi-bin/koha/opac-detail.pl?biblionumber=491\& query_desc=au\%3AEspinoza\%20Soriano\%2C\%20Waldemar\%20and\%20su-to\%3AEtnolog\%C3\%ADa

Euroinnova Formación. (2017). Asesoramiento, Venta y Comercialización de Productos y Servicios Turísticos (Online). Recuperado de file:///C:/Users/temporal/Downloads/Uf0078-Asesoramiento-Venta-YComercializacion-De-Productos-Y-Servicios-Turisticos-Online.pdf

Fernández, A. (febrero, 2015). Ruinas del Cerro Paratón: Ciudadela de Wallibamba. Revista Paratón. Callayuc. Cutervo.

Fundación CODESPA. (2011). Modelo de gestión del turismo rural comunitario de CODESPA. Lima: Tarea Asociación Gráfica Educativa.

Fundación UADE. (2009). Barómetro del turismo mundial. Madrid. Recuperado de https:/l www.biblio.uade.edu.ar/client/es

Gómez, N. (2010). Promoción turística a través de los Medios Audiovisuales, Caso Medellín (Tesis de maestría). Colombia: Universidad Internacional de Andalucía. ISBN 978-84-694-0233-7.

Graziano, J. (2010) Gastronomía tradicional altoandina: Allin Mikuy / Sumak Mikuy. Santigao: FAO.

Hernández, R. (2014). Metodología de la investigación científica (6ª ed.). Ciudad de México: Mac Grown Hill.

llucán (2016). Prensa Cutervo. Prensa. Recuperado de http://www.radioilucan.com/item/311-parque-nacionalde-san-andres.html

INEI. (2010). Platos típicos regionales. Perú: consumo per cápita de los principales alimentos (2008 - 2009).

Instituto Geológico Minero y Metalúrgico - IGMyM. (2007). Informe Técnico Geologíco Ambiental. Peligro Geológico en el Poblado de Huambos. Lima: IGMM.

Lauer, M. (2010). Bodegón de bodegones. Comidas y artes visuales del Perú. Lima: USMP.

Lévano, R. I. (2016). Regulación del turismo rural comunitario en países de Latinoamérica. Lima: Congreso de la República. 
Ruta turística Señorío de los Huambos para el turismo rural comunitario. Alternativa para el desarrollo del turismo y la economía inclusiva

Maeda, J. (2005). Cicán, estado prehispánico, la estancia y la hacienda. Revista de Educación, Cultura y Sociedad, UNPRG, 9. Dic. 850.

Marreros, L. (2003). Nuestro Templo San Juan Bautista. Revista La Pregonada Huambos Perú, 001, 2-3.

Marreros, L. (2004). El sabio Raimondi pasó por Huambos. Revista La Pregonada Huambos Perú, 1,4-6.

Marreros, L. (2007). La historia que nos pertenece. Del quechua Wampu al español Huambos. Revista La Pregonada Huambos Perú, 014, 2-4.

Martínez de Compañón, \& Bujanda, B. J. (2012). Truxillo del Perú, Siglo XVIII. Vol. I y II. Colección Manuscritos Reales de América. Madrid: Real Biblioteca de Madrid.

Martínez, G. (2010). Qhapaq Ñan: El Camino Inca y las Transformaciones Territoriales en los Andes Peruanos. Revista Arqueología y Sociedad, 21, UNMSM.

Mateo, A. (2011). Estudio de pre-factibilidad para la instalación de un hospedaje para turistas que experimentarán turismo vivencial, en la provincia de Tarma. Lima: PUCP.

MINCETUR. (2017) Plan estratégico de turismo rural comunitário. Lima: Mincetur.

Murphy, K., \& Davidshofer, C. (1988). Psychological Testing: Principles and Applications. Michigan: Prentice Hall.

Neira, E. (2012). Huambinos en y para la historia. Revista La Pregonada, XIV, 4-6.

Omaña, C. (2017). Documento de Análisis y Diseño del Sistema Adaptativo de Visitas Guiadas (SAVG). Bogota: Universidad Javeriana.

Organización Mundial del Turismo y Red Española del Pacto Mundial de Naciones Unidas - OMT y REPMNU) (2016). El sector turístico y los Objetivos de Desarrollo Sostenible - Turismo responsable, un compromiso de todos. Madrid: Edamel.

Olivas, R. (1995). La academia de la Olla. Lima: USMP.

Osorio, E. (2019). Propuesta de Ruta Turística Señorío de los Huambos para el Turismo Rural comunitario, en la provincia de Chota, Cutervo y Santa Cruz, Región Cajamarca, 2019 (Tesis de maestría). Universidad de San Martín de Porres, Lima.

Palacios, M. (4 de setiembre de 2018). En America del Sur, Perú es el único país con arte para la cocina, entrevista a Johan Leuridan Huys. Diario Perú 21. Recuperado de https://peru21.pe/cultura/johan-leuridanhuys-america-sur-peru-unico-arte-cocina-424981-noticial

Pérez, G. (2009). Plan de negocios para la implementación de una posada enfocada al turismo alternativo. Lima: PUCP.

PROMPERÚ. (2003). Comisión para la promoción del Turismo. Perfil del Potencial Viajero Nacional. Lima: PE.

Ramos, A., \& Fernández, G. (2013). La educación ambiental: un instrumento para el turismo sustentable. Revista Hospitalidad, 2, 296-312.

Ramos, P. (2005). Mirando al Bosque de Pagaibamba. Revista La Pregonada, Huambos, 007.

Rivera, R. (2011). El sitio arqueológico Incahuasi. Revista La Pregonada, Huambos, XII, 4-6.

Roncal, M., \& Chávez, J. (2016). Recursos turísticos del distrito de Chota y alrededores. Cajamarca: UNC.

Sánchez, O. (2015). Así nació La Ronda, construcción de las Rondas Campesinas. Chota: Ediciones MAVI.

Sariego, I., Pons, J., \& Serrano, M. (2016). El turismo en un entorno nuevo y cambiante. El turismo comunitario como práctica de desarrollo de las áreas rurales del Perú. Lima: aecit.org

Sepúlveda, H., Basurto, R., \& Vizcarra, Y. (2010). Plan estratégico para el desarrollo del turismo rural comunitario en la Región Cusco (Tesis de maestría). Pontificia Universidad Católica del Perú, Lima, Perú. 
Sucuy, L. (2017). Diseño de un producto de turismo rural comunitario para la operadora de turismo Kacha Optur S. A. parroquia Cacha, cantón Riobamba. Ecuador (Tesis de grado). Recuperado de http:// dspace.espoch.edu.ec/handle/123456789/6545

SUNARP. (2017). Guía general, para la inscripción de actos, de las rondas campesinas y comunales. Lima: SUNARP.

Vargas, P., \& Fernández, C. (2010). Propuesta de un modelo de gestión orientado al desarrollo sostenible del turismo, en la provincia de Santa Cruz región de Cajamarca, 2009. Lima: UCV-Sciencia.

Vílchez, S. (1945). Breve visión de Cutervo. Indiana: Bracamonte.

Vílchez, S. (1960). Fusiles y machetes. Texas: Amauta.

Vílchez, S. (1968). Parques Nacionales del Perú. Recuperado de https://www.bibliotecavirtualmunicutervo.gob.pe/ essential_grid/salomon-vilchez-murga/

Villanueva, V. (2010). El camino de la quinua. Lima: Movimiento Manuela Ramos. 